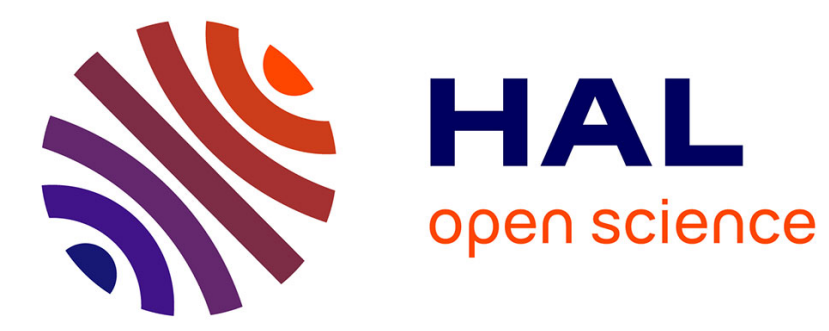

\title{
Development of sex stereotypes relative to sport competence and value during adolescence
}

\author{
Julie Boiché, Aïna Chalabaev, Philippe Sarrazin
}

\section{To cite this version:}

Julie Boiché, Aïna Chalabaev, Philippe Sarrazin. Development of sex stereotypes relative to sport competence and value during adolescence. Psychology of Sport and Exercise, 2014, 15, pp.212-215. 10.1016/j.psychsport.2013.11.003 . hal-00947283

\section{HAL Id: hal-00947283 \\ https://hal.science/hal-00947283}

Submitted on 15 Feb 2014

HAL is a multi-disciplinary open access archive for the deposit and dissemination of scientific research documents, whether they are published or not. The documents may come from teaching and research institutions in France or abroad, or from public or private research centers.
L'archive ouverte pluridisciplinaire HAL, est destinée au dépôt et à la diffusion de documents scientifiques de niveau recherche, publiés ou non, émanant des établissements d'enseignement et de recherche français ou étrangers, des laboratoires publics ou privés. 
RUNNING TITLE: Development of sport gender stereotypes

\section{Paper accepted by the journal "Psychology of Sport and Exercise"}

on September 10th 2013

Development of gender stereotypes relative to sport competence and value during adolescence

Julie Boiché ${ }^{1,2}$

Aïna Chalabaev ${ }^{3}$

Philippe Sarrazin ${ }^{4}$

${ }^{1}$ Laboratory Epsylon, France

${ }^{2}$ University Montpellier 1, France

${ }^{3}$ University of Paris West Nanterre La Defense, France

${ }^{4}$ University Joseph Fourier Grenoble 1, Laboratoire "Sport et environnement social”, France

Correspondence concerning this article should be addressed to:

Julie Boiché

Laboratory Epsylon "Dynamics of Human Abilities and Health Behavior" (EA 4556)

4 Boulevard Henri IV

34000 Montpellier

France.

UFR STAPS

University Montpellier 1

700 Avenue du Pic-Saint-Loup

34090 Montpellier

France

E-Mail: julie.boiche@univ-montp1.fr

Phone : +33411759081

Voice : +33467601194 
Aïna Chalabaev

University Paris Ouest Nanterre La Défense

UFR STAPS

Bât.S, bur.102

200 avenue de la République

92001 NANTERRE

France

Email: aina.chalabaev@u-paris10.fr

Philippe Sarrazin

University Joseph Fourier Grenoble 1

Laboratory "Sport et Environnement Social"

1741 rue de la Piscine

Domaine universitaire

Saint Martin d'Hères

France

Email: philippe.sarrazin@ujf-grenoble.fr 


\section{DEVELOPMENT OF SEX SPORT STEREOTYPES}

\section{Abstract}

2 Objectives. Sex stereotypes adoption is presumed to impact one's perceived competence and

3 value and to ultimately lead to dropout of certain activities. Adolescence is deemed to

4 represent a period during which sex stereotypes are reinforced. The purpose of this study was

5 to examine through a longitudinal design how sex stereotypes concerning athletic competence

6 and value differ across adolescence. Design. A three-wave longitudinal follow-up within five

7 cohorts of adolescents $(N=718)$ was realized. Method. The participants completed a

8 questionnaire assessing indirectly sport value and sport competence sex stereotypes. Results.

9 Multilevel growth curve analyses indicated that (i) boys report higher levels of stereotypes,

10 (ii) the level of stereotypes endorsement increases with age, (iii) the rate of change of

11 stereotypes endorsement decreases, and (iv) its increase is more pronounced among girls.

12 Conclusions. The hypothesis of an increase of sport stereotypes attached to sport is confirmed 13 among girls. Methodological shortcomings are underlined and research perspectives are 14 advanced. 


\section{DEVELOPMENT OF SEX SPORT STEREOTYPES}

\section{Development of sex stereotypes relative to sport competence and value during}

\section{adolescence}

Adopting an active lifestyle is associated with positive youth development (Mahoney, Harris, \& Eccles, 2006), the quality of cognitive executive functioning (Guiney \& Machado, 2013), and physical health across the lifespan (Bauman, 2004). Because adolescence

represents a key period regarding extra-curricular activities such as sport (Boyd \& Bee, 2008), it is crucial to identify the factors likely to affect sport participation in youth. Social psychologists advance that such decisions are partly influenced by sex stereotypes (Fredricks \& Eccles, 2005), that is "shared social beliefs regarding the characteristics — both personality traits and behaviors — of social groups" (Leyens, Yzerbyt, \& Schadron, 1994). Despite significant changes in the latter decades, sport is still viewed as a "male area" in western countries, and recent reports indicate that boys / men still participate more in sports, compared to girls / women (e.g., van Tuyckom, Scheerder, \& Bracke, 2010).

According to a recent review (Chalabaev, Sarrazin, Fontayne, Boiché, \& ClémentGuillotin, 2013), there are two main pathways in which sex stereotypes manifest in sporting contexts. First, as long as it is known by the individual, a stereotype can operate directly and affect his/her performance if it is activated in a valued situation (e.g., Chalabaev, Sarrazin, Stone, \& Cury, 2008). Stereotypes can also operate indirectly, through an internalization process. One of the most fruitful theoretical frameworks devoted to the understanding of sex stereotypes transmission and internalization is the Eccles and collaborators' ExpectancyValue Model (EVM; Eccles, Freedman-Doan, Frome, Jacobs, \& Yoon, 2000). According to this model, the two most proximal variables determining a young individual's choices and behaviors are his/her expectations of success in the activity and the value that he/she places into it. Expectations of success are the chances of success estimated in a given situation, and are assumed to be directly related to perceived ability or competence (Eccles et al., 2000). 


\section{DEVELOPMENT OF SEX SPORT STEREOTYPES}

1 Numerous studies observed a significant link between expectations of success or perceptions

2 of competence, and physical activity or sport involvement in youth. Researchers reported

3 significant correlations between such perceptions and the time spent being physically active

4 (e.g., Bois, Sarrazin, Brustad, Trouilloud, \& Cury, 2005; Eccles \& Harold, 1991), and a

5 negative bound between perceived competence and dropout from the activity (Guillet,

6 Sarrazin, Fontayne, \& Brustad, 2006). Next, subjective value refers to the relative importance

7 accorded to do well in the activity, its perceived usefulness, the inherent interest, potential

8 positive outcomes, and costs attached to engaging in it. The importance, usefulness, and

9 interest aspects of value were the most studied, and were found to be positively associated

11 (Guillet et al., 2006).

Past research consistently observed significant differences in favour of boys and men in the levels of perceived competence and value in sport (e.g., Fredricks \& Eccles, 2005).

Eccles' (EVM) suggests that those differences are partly due to the endorsement of stereotypes attached to the sport context (Eccles et al., 2000). Recent research supports this hypothesis, indicating that the more adolescents adhere to stereotypes in favour of the other sex, the less they feel competent and value their sport, and the less they intend to pursue it (Authors, in press, Study 2). Dropout athletes were also found to endorse to a greater extent sport competence stereotype in favour of the opposite gender (Authors, in press, Study 1). Taken together, those results sustain the view that female adolescents who endorse pro-male stereotypes relative to the sport area will tend to perceive themselves as less competent and to value sport to a lower extent, and should be more prone to stop their participation.

According to Hill and Lynch (1983), adolescence represents a crucial developmental period during which gender stereotypes are assimilated, in relationship with the pubertal processes that increase the salience of gender. However, empirical studies exploring this issue 


\section{DEVELOPMENT OF SEX SPORT STEREOTYPES}

1 remain scarce and are for the large part cross-sectional. The longitudinal studies of Galambos,

2 Almeida, and Petersen (1990), and of Alfieri, Ruble, and Higgins (1996) constitute exceptions

3 with this regard. Alfieri et al. (1996) interrogated $4^{\text {th }}$ to $8^{\text {th }}$ graders about the appropriateness

4 for boys/men and girls/women of certain stereotypical activities and traits. They observed that

5 the flexibility of gender roles (i.e., appropriate for both girls and boys) increases after they

6 transitioned from elementary to high school but then decreases. Galambos and colleagues

7 (1990) observed among $6^{\text {th }}$ to $8^{\text {th }}$ grade that boys significantly scored lower on scales

8 expressing beliefs in gender equality, compared to girls. If no developmental studies in the

9 sport area examined the evolution gender stereotypes, a handful of studies examined the

10 developmental trends of perceived sport competence and value as a function of sex. They

11 consistently indicated that those perceptions decrease during childhood and adolescence

12 (Jacobs et al., 2002; Marsh, 1989; Wigfield et al., 1997). They also reported that boys

13 perceived themselves as more competent in sport than girls during these developmental

14 periods, that they valued sport more than girls, and that gender differences in those

15 perceptions tended to increase (Jacobs et al., 2002; Marsh, 1989; Wigfield et al., 1997).

The EVM (Eccles et al., 2000) suggests that self-perceptions partly result from gender stereotypes internalization into the self. If a significant proportion of adolescents endorse more and more pro-male stereotypes in the sport domain, sport-related self-perceptions of competence and value should be increasingly lower in adolescent females, compared to males. Past studies (Jacobs et al., 2002; Marsh, 1989; Wigfield et al., 1997) are consistent with this hypothesis of an increased endorsement of gender stereotypes relative to sport, but did not directly test it. The purpose of this three-wave longitudinal study was precisely to investigate the evolution of gender stereotypes relative to sport during adolescence. Based on Eccles' model, two stereotypes were studied: the belief that sport is more important for boys than for girls (value) and the belief that boys are more competent in sport, compared to girls 


\section{DEVELOPMENT OF SEX SPORT STEREOTYPES}

1 (competence). It was expected that pro-masculine stereotypes endorsement would increase

2 during adolescence and both linear and quadratic changes were examined. Considering the

3 gender effects observed in past research (Galambos et al., 1990), it was hypothesized that

4 boys would report higher scores than girls.

\section{Method}

\section{Participants and Procedure}

Data for these analyses come from a longitudinal study of students from $6^{\text {th }}$ through

$12^{\text {th }}$ grade, relative to the Perceptions of Sport during Adolescence (Boiché \& Sarrazin, 2007).

The study was conducted in France between 2004 and 2006 and explored several psychosocial variables likely to account for sport motivation, including sex stereotypes.

During the first wave of data collection, students from $6^{\text {th }}, 7^{\text {th }}, 8^{\text {th }}, 9^{\text {th }}$, and $10^{\text {th }}$ grades participated. Those cohorts were followed through the next two waves of data collection. In France, high school is divided into junior high school - for students aged about 11 to 15 years in grades 6 through 9 - and senior high school - for students aged about 15 to 18 years in grades 10 through 12 . The high schools in which the data were collected were public and welcomed students from a variety of backgrounds - lower, middle and upper-class - in a middle-size city (one hundred and fifty thousand inhabitants). The sample comprised adolescents living in an urban or suburban area and was representative of the French adolescent population in terms of academic profile and socioeconomic background. Overall, 1015 students participated at wave 1; 790 at wave 2; and 893 at wave 3 , and only 368 students participated at all three times of data collection. The analyses were conducted on those 718 students who participated in at least 2 waves of data collection ( $47 \%$ of boys at wave 1$)$.

\section{Measures}

Endorsement of sport-related sex stereotypes. The measure developed by Bonnot and Croizet (2007) was used in the current study. Because traditional scales (e.g., "Men are better 


\section{DEVELOPMENT OF SEX SPORT STEREOTYPES}

1 than women at sports") can generate strong social desirability biases (Chalabaev et al., 2013),

2 stereotypes endorsement was assessed by two items through which participants evaluated

3 separately boys and girls on 7-point Likert scales. Two stereotypes were assessed, sport

4 competence: "Personally, I think that performance of boys in sport is..."; "Personally, I think

5 that performance of girls in sport is..."; answers ranging from 1 (very poor) to 7 (very good),

6 and sport value: "Personally, I think that for boys doing sport is..."; "Personally, I think that

7 for girls doing sport is..."; answers ranging from 1 (not important at all) to 7 (very

8 important). For each stereotype, the score attributed to girls was subtracted to the one given to

9 boys so that positive scores reflect pro-male stereotypes, negative scores pro-feminine 


\section{DEVELOPMENT OF SEX SPORT STEREOTYPES}

1 interaction between sex and age (to test whether this evolution differed for males and

2 females).

\section{Results}

Two models were tested regarding the predictors of gender sport stereotype relative to competence and value, respectively (see Table 1). Concerning sport competence, the effects of three parameters were significant: (a) males reported higher levels of pro-masculine stereotypes endorsement, compared to females; (b) the level of stereotype endorsement globally increased during the period studied; (c) this evolution was not linear, it was strong at the beginning of this period but then slowed (see Figure 1). There was also a marginal interaction effect between age and gender, suggesting that the endorsement of this stereotype was slightly stronger within females during the period studied. Regarding sport value, all predictors included in the model appeared as significant: (a) males reported higher levels of stereotypes endorsement, compared to females; (b) the level of this stereotype endorsement tended to increase as individuals get older in the period of secondary studies; (c) the rhythm of evolution slowed at the end of adolescence and (d) the rate of change was more pronounced among females, compared to males (see Figure 1).

\section{Discussion}

Regular physical activity is recognized for its many benefits in terms of social, cognitive and physical development (Bauman, 2004; Guiney \& Machado, 2013; Mahoney et al., 2006). Yet, there continues to be significant sex differences in terms of length and intensity of participation, which are in disfavour of women in most European countries (van Tuyckom et al., 2010). Eccles and colleagues’ EVM (Eccles et al., 2000) assumes that a complex causal chain linking the internalisation of environmental stereotypes to negative selfperceptions of competence and value would contribute to such unbalance. However, little is known on the evolution of stereotypes endorsement during adolescence. Adopting a three- 


\section{DEVELOPMENT OF SEX SPORT STEREOTYPES}

1 wave longitudinal design within five cohorts of adolescents, the current study obtained a

2 clearer picture of these developmental trends.

As a whole, it appears that boys display significantly higher levels of pro-masculine

4 stereotypes endorsement, compared to girls, which is in line with past results (Galambos et

5 al., 1990). Our data further indicated that the hypothesis of an increase of stereotypes was

6 mostly verified among females, males tending in average to already hold pro-masculine views

7 of sport when they begin secondary studies. The greater disparities between sexes are reported

8 at the beginning of adolescence, whereas boys and girls apparently adhere similarly to pro-

9 masculine stereotypes at the end of adolescence. This evolution may partly explain why sport

10 participation decreases more dramatically among girls during adolescence (van Tuyckom et 11 al., 2010). Also, it appears that stereotypes relative to sport value are mostly in favour of 12 one's sex at the beginning of this period, whereas both boys and girls show slightly pro-male 13 beliefs at the end of it. This pattern of results is in line with some age differences observed in 14 a cross-sectional study relative to racial stereotypes by Copping and her collaborators 15 (Copping, Kurtz-Costes, Rowley, \& Wood, 2013). The authors concluded that early 16 adolescence represented a developmental period during which there is a shift between in17 group biases to views that are consistent with beliefs in the wider society. observed in the study. First, actors of the social environment such as parents could be more likely to transmit pro-masculine stereotypes to male children, as they are favorable to them. More communication suggesting that sports represent a masculine domain in the direction of boys could explain this earlier embracement of stereotypes. For instance, it was shown that parents of boys spent more time watching sports on television, compared to parents of girls (Eccles et al., 2000). Besides, it is well established that women sports only represents a small part of events presented on television (7\% in France according to a recent study of the 


\section{DEVELOPMENT OF SEX SPORT STEREOTYPES}

1 Superior Council for Broadcasting, 2013). This may also result from a difference of

2 perception: even if faced with similar quantity of information conveying gender stereotypes

3 relative to sport, females could be less prone to adhere to a social perspective in disfavor of

4 their gender. Last, the degree of endorsement seems to increase within females at a period

5 where physical differences are increasing between sexes. It is possible that beliefs in gender

6 equality are more difficult to sustain in the face of clear differentiation in height or strength.

7 Of course, those potential explanations remain speculative and their validation is beyond the 8 scope of the present article.

In spite of its innovative character, the current study is not exempt of certain limitations. A first limitation is linked to its sample's representativeness. Because we cooperated with high schools devoted to general studies, we did not consider the small percentage of French teenagers who either drop out from school or choose a more professional training. Past research indicated that more sexism is associated with lower educational levels (e.g., Pearson, 2009), suggesting that the levels of stereotypes observed would be higher when incorporating all adolescents of a given generation. Second, this study was based on a self-report scale to assess gender stereotypes. Even if the tool selected was aimed at limiting potential biases, certain scholars propose to include implicit tests, such as the Implicit Association Test, in research designs. For example, Cvencek, Meetzoff, and Greenwald (2011) used such a procedure to investigate sex stereotypes related to mathematics in American children. Future studies in the sport context could consider a similar perspective. In conclusion, it seems that adolescence does represent a developmental period in which gender stereotypes relative to sport become stronger in girls. The presence of this kind of beliefs is likely to lead to a disengagement from this context. This can be seen as problematic considering the importance of early lifestyle choices in ulterior sedentary versus active habits, and the health benefits of regular physical activity through the lifespan. 


\section{DEVELOPMENT OF SEX SPORT STEREOTYPES}

\section{References}

Alfieri, T., Ruble, D. N., \& Hggins, E. T. (1996). Gender stereotypes during adolescence: Developmental changes and the transition to junior high school. Developmental Psychology, 32, 1129-1137. doi:10.1037/0012-1649.32.6.1129

[Authors] (in press). Social antecedents and consequences of gender stereotypes relative to sport during adolescence. Psychology of Women Quarterly.

Boiché, J. C. S., \& Sarrazin, P. G. (2007). Self-determination of contextual motivation, intercontext dynamics and adolescents' patterns of sport participation over time. Psychology of Sport and Exercise, 8, 685-703. doi:10.1016/j.psychsport.2006.10.004

Bauman, A. E. (2004). Updating the evidence that physical activity is good for health: An epidemiological review 2000-2003. Journal of Science and Medicine in Sport, 7, 6-19.

Bois, J. E., Sarrazin, P. G., Brustad, R. J., Trouilloud, D. O., \& Cury, F. (2005). Elementary schoolchildren's perceived competence and physical activity involvement: The influence of parents' role modelling behaviours and perceptions of their child's competence. Psychology of Sport and Exercise, 6, 381-397. doi:10.1016/j.psychsport.2004.03.003

Bonnot, V., \& Croizet, J.-C. (2007). Stereotype internalization and women's math performance : The role of interference in working memory. Journal of Experimental Social Psychology, 43, 857-866. doi:10.1016/j.jesp.2006.10.006

Boyd, D., \& Bee, H. (2008). Lifespan development (5th Ed.). Boston, MA: Pearson Education.

Chalabaev, A., Sarrazin, P., Fontayne, P., Boiché, J., \& Clément-Guillotin, C. (2013). The influence of sex stereotypes and gender roles on sport participation and performance: Review and future directions. Psychology of Sport and Exercise, 14, 136-144. doi:0.1016/j.psychsport.2012.10.005 


\section{DEVELOPMENT OF SEX SPORT STEREOTYPES}

1 Chalabaev, A., Sarrazin, P., Stone, J., \& Cury, F. (2008). Do Achievement Goals Mediate Stereotype Threat? An Investigation on Females' Soccer Performance. Journal of Sport and Exercise Psychology, 30, 143-158.

Copping, K. E., Kurtz-Costes, B., Rowley, S. J., \& Wood, D. (2013). Age and race differences in racial stereotype awareness and endorsement. Journal of Applied Social Psychology, 43, 971-980. doi:10.1111/jasp.12061

Cvencek, D., Meltzoff, A. N., \& Greenwald, A. G. (2011). Math-gender stereotypes in elementary-school children. Child Development, 82, 766-789. doi:10.1111/j.14678624.2010.01529.x

Eccles, J. S., Freedman-Doan, C., Frome, P., Jacobs, J., \& Yoon, K. S. (2000). Gender role socialization in the family: A longitudinal approach. In T. Eckes \& H. Trautner (Eds.), The developmental social psychology of gender (p. 333-360). Mahwah, NJ: Lawrence Erlbaum Associates.

Eccles, J. S., \& Harold, R. D. (1991). Gender differences in sport involvement: Applying the Eccles’ expectancy-value model. Journal of Applied Sport Psychology, 3, 7-35. doi:10.1080/10413209108406432

Fredricks, J. A., \& Eccles, J. S. (2005). Family socialization, gender, and sport motivation and involvement. Journal of Sport and Exercise Psychology, 27, 3-31.

Galambos, N. L., Almeida, D. M., \& Petersen, A. C. (1990). Masculinity, femininity, and sex role attitudes in early adolescence: Exploring gender intensification. Child Development, 61, 1905-1914. doi:10.1111/j.1467-8624.1990.tb03574.x

Guillet, E., Sarrazin, P., Fontayne, P., \& Brustad, R. (2006). Understanding girl sport attrition in a stereotypical boy sport within the framework of Eccles's expectancy-value model. Psychology of Women Quarterly, 30, 358-368. doi:10.1111/j.1471-6402.2006.00311.x

Guiney, L., \& Machado, L. (2013). Benefits of regular aerobic exercise for executive 


\section{DEVELOPMENT OF SEX SPORT STEREOTYPES}

functioning in healthy populations. Psychonomic Bulletin \& Review, 20, 73-86. doi:10.3758/s13423-012-0345-4

Hill, J. P., \& Lynch, M. E. (1983). The intensification of gender-related role expectations during early adolescence. In J. Brooks-Gunn \& A. C. Petersen (Eds.), Girls at puberty (pp. 201-228). New York: Plenum Press.

Jacobs, J. E., Lanza, S., Osgood, W. D., Eccles, J. S., \& Wigfield, A. (2002). Changes in children's self-competence and values: Gender and domain differences across grades one through twelve. Child Development, 73, 509-527. doi:10.1111/1467-8624.00421

Leyens, J.-Ph., Yzerbyt, V. Y., \& Schadron, G. (1994). Stereotypes, social cognition, and social explanation. London: Sage.

Mahoney, J. L., Harris, A. L., \& Eccles, J. S. (2006). Organized activity participation, positive youth development, and the over-scheduling hypothesis. Social Policy Report, 20, 331.

Marsh, H. (1989). Age and sex effects in multiple dimensions of self-concept: Preadolescence to early adulthood. Journal of Educational Psychology, 81, 417-430. doi:10.1037/0022-0663.81.3.417

Pearson, C. (2009). Predictors of sexist attitudes in a Mexican American adult sample: A test of Glick and Fiske's ambivalent sexism theory. Unpublished Dissertation: Fielding Graduate University, Santa Barbara, CA.

Raudenbush, S. W., \& Bryk, A. S. (2002). Hierarchical linear models: Applications and data analysis methods ( $2^{\text {nd }}$ Ed.). Thousand Oaks: Sage.

Superior Council for Broadcasting. (2013). Women sports on television [Le sport féminin à la télévision]. Article retrieved on http://www.csa.fr/Etudes-et-publications/Les-dossiersd-actualite/Le-sport-feminin-a-la-television on March $19^{\text {th }} 2013$. 


\section{DEVELOPMENT OF SEX SPORT STEREOTYPES}

1 Van Tuyckom, C., Scheerder, J., \& Bracke, P. (2010). Gender and age inequalities in regular

4 Wigfield, A., Eccles, J. S., Yoon, K. S., Harold, R. D., Arbreton, A. J. A., Freedman-Doan, C. 5 sports participation: A cross-national study of 25 European countries. Journal of Sports Sciences, 28, 1077-1084. doi:10.1080/02640414.2010.492229 et al. (1997). Changes in children's competence beliefs and subjective task values across the elementary school years: A three-year study. Journal of Educational Psychology, 89, 451-469. doi:10.1037/0022-0663.89.3.451 


\section{PERCEIVED RELATIONSHIPS BETWEEN LIFE CONTEXTS - 15 -}

Table 1: Results of the growth curve analyses on stereotype endorsement during adolescence

\begin{tabular}{|c|c|c|c|c|}
\hline \multirow[b]{2}{*}{ Variables } & \multicolumn{2}{|c|}{ Sport Competence } & \multicolumn{2}{|c|}{ Sport Value } \\
\hline & Effect & SE & Effect & SE \\
\hline \multicolumn{5}{|l|}{ Fixed Effects } \\
\hline Constante & $-3.604 *$ & 1.871 & $-8.838 *$ & .1 .855 \\
\hline Sex & $0.575 *$ & 0.253 & $1.238 *$ & 0.251 \\
\hline Age & $0.577 *$ & 0.289 & $1.289 *$ & 0.282 \\
\hline $\mathrm{Age}^{2}$ & $-0.019 *$ & 0.009 & $-0.041 *$ & 0.008 \\
\hline Sex $\times$ Age & $-0.034^{\mathrm{t}}$ & 0.019 & $-0.074 *$ & 0.019 \\
\hline \multicolumn{5}{|l|}{ Random Effects } \\
\hline \multicolumn{5}{|l|}{ Level 2 (Individual) } \\
\hline Constante & $0.400 *$ & 0.049 & $0.294 *$ & 0.045 \\
\hline Level 1 (measure) & $1.070 *$ & 0.047 & $1.142 *$ & 0.050 \\
\hline Log Likelihood & 5517.596 & & 5540.259 & \\
\hline
\end{tabular}

Note: An effect is considered as significant at $\mathrm{p}=.05$ when it is at least equal to 1.96 times its ET 


\section{PERCEIVED RELATIONSHIPS BETWEEN LIFE CONTEXTS - 16 -}

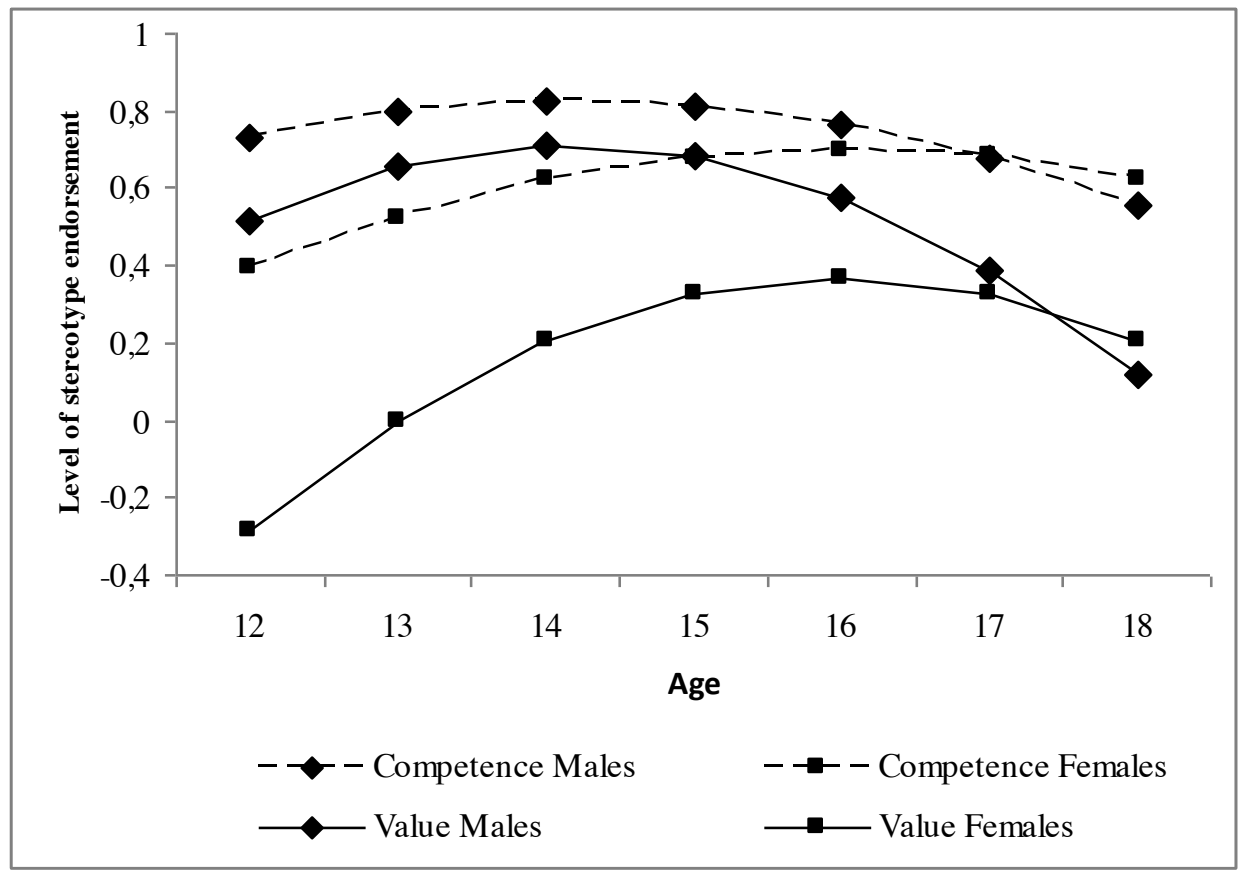

Figure 1: Evolution of Stereotypes Endorsement during Adolescence 
- Sex stereotypes endorsement relative to sport increases during adolescence

- This increase is stronger in early adolescence and then slows down.

- Sex stereotype endorsement is higher in male adolescents, compared to females.

- The increase in sex stereotype endorsement is stronger in females than in males. 